\title{
Structural Pieces Rehabilitation with Self-Tapping Screws
}

\author{
Laurenn Borges de Macedo ${ }^{1}$, Giovana Gobatto Balanco ${ }^{1}$, Nathan Alves dos Santos ${ }^{2}$, Lucas José Marini ${ }^{3}$, \\ Felipe Nascimento Arroyo ${ }^{4}$, André Luis Christoforo ${ }^{4, *}$, Francisco Antonio Rocco Lahr ${ }^{5}$ \\ ${ }^{1}$ Department of Materials Engineering, São Carlos Engineering School, São Paulo University - USP, São Carlos, SP, Brazil \\ ${ }^{2}$ Paulista State University (UNIP), campus Araraquara - SP. Araraquara, Brazil \\ ${ }^{3}$ University Center Central Paulista (UNICEP), São Carlos, Brazil \\ ${ }^{4}$ Centre for Innovation and Technology in Composites (CITeC), Department of Civil Engineering (DECiv), Federal University of São \\ Carlos (UFSCar), São Carlos, Brazil \\ ${ }^{5}$ Department of Structures Engineering (SET), Engineering School of São Carlos of University of São Paulo (EESC/USP), São Carlos, \\ Brazil
}

\begin{abstract}
Timber is one of the oldest raw materials in construction, due to their availability worldwide, and the ease of using it. The majority of buildings in Brazil, until the Industrial Revolution, utilized this material as main input, rooting most of our cultural heritage in it. With the passage of time, as all materials, occurs the deterioration of these structural parts, where occasionally the partial replacement can solve the problem. This study aimed to analyze the relation between the amount of self-tapping screws and the rigidity product of composite mixed pieces of Eucalyptus sp and treated Pinus sp, simulating the rehabilitation of a structural piece in state of degradation, with the replacement of the degraded portion.
\end{abstract}

Keywords Self-tapping screw, Rehabilitation, Flexural stiffness

\section{Introduction}

A wood element was most used by the man construction since the beginnings. Linked to materials such as clay, was used to obtain housing replacing in prehistoric caves. Since that time, wood has been part of the entire construction industry history [1].

The interest in wood and its great use is due to some factors, such as: accessible material, good strength and durability, easy handling and adequacy (roofing), wide lengths variety and diameters, and a very light material when compared to other structural elements, which facilitates their transport and structures assembly [2].

In Brazil, owing to its extensive territorial area and favorable climate, besides other factors, there is a wide diversity of wood species. Due to the large area amount available for planting and various species, here in Brazil, wood was an accessible material in different lengths and diameters, leading to its great use in buildings. Thus, even today, there are very old constructions originating from colonial era and subsequent epochs [3]. However, because they were very old constructions and, for the most part, they did not receive adequate maintenance and care, they were exposed to various degradation agents types that compromised their structural performance and useful life. In

* Corresponding author:

alchristoforo@gmail.com.br (André Luis Christoforo)

Published online at http://journal.sapub.org/ijme

Copyright (C) 2017 Scientific \& Academic Publishing. All Rights Reserved many cases, there are structures with advanced deterioration degree where part of structure has to be removed or even totally replaced. Aiming that, in most cases, the structural element cannot be replaced as a whole, it is necessary to apply alternative methods for rehabilitation [4].

In the attempt of local rehabilitation structural elements in wood, some techniques are proposed by: Cruz and Mendonça [5], Bertolini et al. [3], Custódio and Cabral-Fonseca [6], Nowak et al. [7], Pizzo et al. [8].

The present work aimed to present a viable method of local rehabilitation in wood structural parts through the element partial replacement with help of self-tapping screws and Pinus sp. treated.

\section{Material and Methods}

The tests were carried out at the Wood and Structures Laboratory, Department of Structural Engineering, School of Engineering of São Carlos, University of São Paulo.

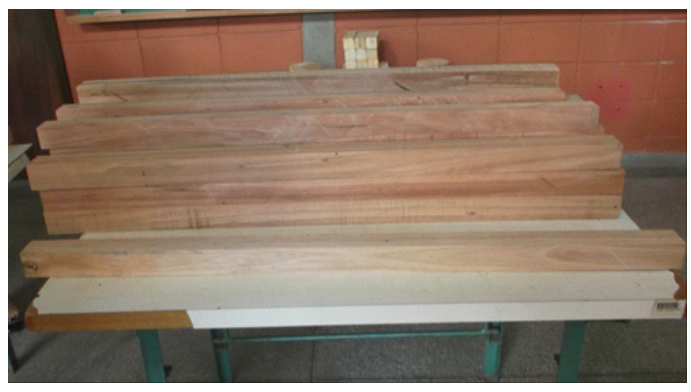

Figure 1. Proof body for static bending test 
Four test specimens were produced according to Brazilian standard ABNT NBR 7190 [9] for static flexural tests (Figure 1) of Eucalyptus sp.

Through the static bending tests it was possible determine the stiffness product (E.I.) of each solid part. Then, a third section of each specimen was removed in an attempt to simulate the removal of structural element degraded part (Figure 2A).

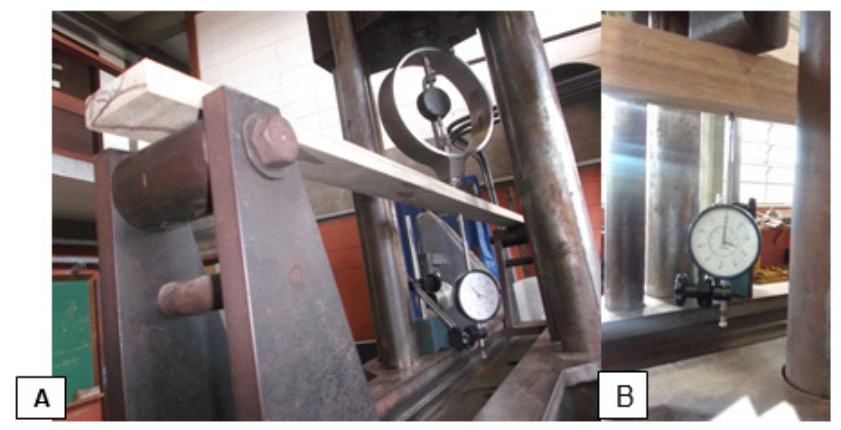

Figure 2. Static bending test on Pinus sp (A) and Eucalyptus sp (B) beam

The second material used was Pinus sp. Specimens with the same width and length values, $5 \mathrm{~cm}$ and $115 \mathrm{~cm}$ respectively, were made, with a height equivalent to the value obtained from Eucalyptus sp., one third of the original $5 \mathrm{~cm}$ piece, that is, $1.6 \mathrm{~cm}$. These new specimens of Pinus also underwent stiffness tests, according to Figure 2B.

Eucalyptus sp. and Pinus sp. with complementary heights, respecting the bodies dimensions of static flexural tests established by NBR 7190 [9], were made mixed pieces of 5 $\mathrm{cm}$ in height fixed firstly with 3 self-tapping screws of $4 \mathrm{~mm}$ in diameter and $50 \mathrm{~mm}$ in length (Figure 3), resulting in Treatment 1 .

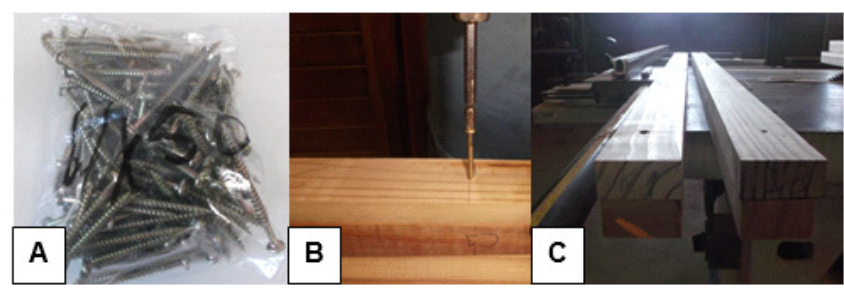

Figure 3. $4 \times 50 \mathrm{~mm}$ screws (A); Screws installation for joining two beams (B); Treatment 1 , mixed beam (C)

In this treatment, because it was the first, was necessary to fix the cap screws to the equivalent distance of 4 times the screw diameter (Figure 4) in relation to supports used during the tests (ABNT NBR 7190 [9]). The third screw of Treatment 1 was attached in the piece center. In Figure 4, "d" is screw diameter.

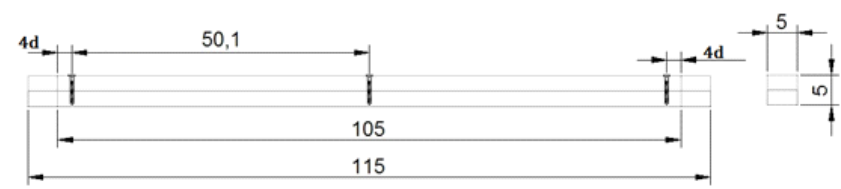

Figure 4. Treatment 1 - mixed piece with 3 screws along the effective span

After Treatment 1 , the same mixed parts were used to obtain Treatment 2, which were fastened 2 additional screws located, one between the left and center screw and the other between the middle screw and the right one, resulting in 5 equidistant screws. After treatment 2 , screws number was increased three more times, always adding screws between the already existing ones, resulting in the treatments 3,4 and 5 that have, respectively, 9, 17 and 33 screws (Figure 5) along the effective span of $105 \mathrm{~cm}$, emphasizing that with each new treatment, new flexural tests were carried out to obtain the stiffness product.

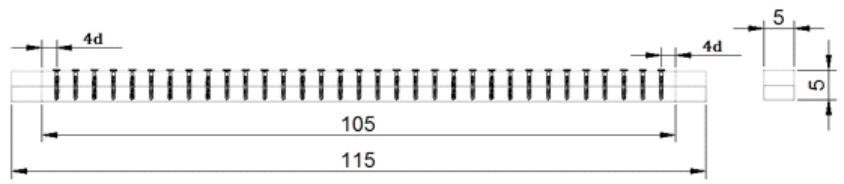

Figure 5. Treatment 5, mixed piece with 33 screws along the effective span

The screws number influence [NP] (0 [100\% Eucalyptus wood], $3 ; 5 ; 9 ; 17 ; 33)$ on beams flexural stiffness (EI) $(1 / 3$ Pinus $+2 / 3$ Eucalyptus) was investigated by the analysis of variance (ANOVA), with help of software Minitab ${ }^{\circledR}$ version 14. The ANOVA was considered at the $5 \%$ significance level $(\alpha)$, having as null hypothesis $\left(\mathrm{H}_{0}\right)$ the equivalence between the group's means, and the non-equivalence as an alternative hypothesis $\left(\mathrm{H}_{l}\right)$. By ANOVA formulation, P-value (probability $\mathrm{P}$ ) higher than the significance level $(0,05)$ implies accepting $\mathrm{H}_{0}$ (statistically equivalent means), rejecting it otherwise (means significantly different) [10].

Were used, to verify the normality and homogeneity of the group variances (ANOVA validation), the Anderson-Darling (AD) and Bartlett $(\mathrm{Bt})$ test, respectively, both of which were also evaluated at the $5 \%$ significance level. By validations tests formulation, P-value higher than the significance level implies that the distributions by property are normal and that the variances are homogeneous.

The Tukey test was used to compare the groups, making it possible to identify the ones with the highest mean value in flexural stiffness values. From Tukey test, also evaluated at $5 \%$ significance level, "A" indicates the group with highest mean value; "B" with the second highest mean; and "C" treatments with equivalent means.

Four determinations were obtained from flexural tests for each experimental condition, differentiated only by screws number, considering also the reference condition (without screws - beams made with $100 \%$ Eucalyptus wood).

After investigating the influence of the screws number factor on flexural stiffness of mixed beams, regression models (Equations 1 to 4 ) based on analysis of variance were tested in order to establish the best fit between the screws number and stiffness in flexion.

$$
\begin{array}{ll}
Y=a+b \cdot X & {[\mathrm{Lin}]} \\
Y=a \cdot e^{b \cdot X} & {[\mathrm{Exp}]} \\
Y=a+b \cdot \operatorname{Ln}(X) & {[\mathrm{Log}]} \\
Y=a \cdot X^{b} & {[\mathrm{Geo}]}
\end{array}
$$


By regression models ANOVA, considered at the 5\% significance level $(\alpha)$, the null hypothesis formulated consisted in non-representativeness of the models tested $\left(\mathrm{H}_{0}\right.$ : $\beta=0$ ), and in the representativeness as alternative hypothesis $\left(\mathrm{H}_{1}: \beta \neq 0\right)$. $\mathrm{P}$-value higher than significance level considered implies accepting $\mathrm{H}_{0}$ (the model tested is not representative variations of $X$ are unable to explain the variations in $Y$ ), refuting it otherwise (the model tested is representative). In addition to ANOVA, which allows to accept the models tested representativeness, the coefficient values of determination $\left[\mathrm{R}^{2}\right]$ were obtained as a way of evaluating the variations capacity of the independent variable $X$ in explaining the predictive variable $Y$, among the models considered significant, those with the best fit between flexural stiffness and screws number [10].

Compression test parallel to the fibers of Eucalyptus $s p$. wood in agreement with NBR 7190 [9] (Figure 6B) was also carried out in order to obtain the wood resistance class.

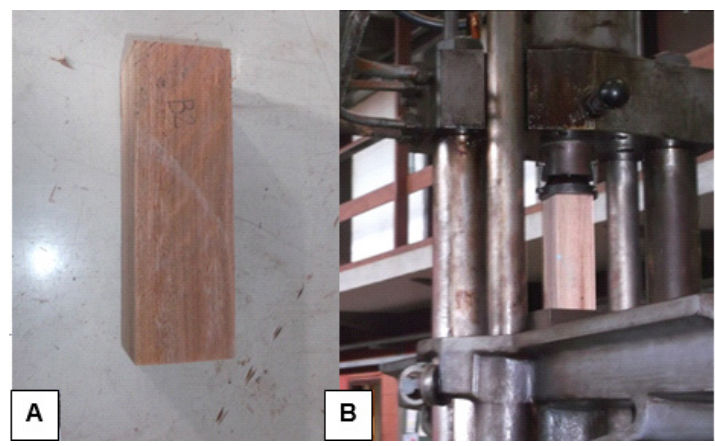

Figure 6. Eucalyptus $s p$. test specimens for parallel fiber compression test (A); Parallel compression test with Eucalyptus sp. (B)

\section{Results and Discussions}

Table 1 presents the mean values ( $\bar{x})$, variation coefficients (Cv), the lowest (Min) and largest (Max) flexural stiffness (EI) values of the beams for each screw configuration tested along with the reference condition (without screw - 0), and Figure 7 illustrates the mean values variations with the screws number.

Table 1. Flexural stiffness results of tested beams

\begin{tabular}{cccc}
\hline \multicolumn{4}{c}{ EI $\left(\mathbf{N} \cdot \mathbf{m}^{2}\right)$} \\
\hline Statistics & 0 par. & 3 par. & 5 par. \\
\hline $\bar{x}\left(\mathrm{~N} \cdot \mathrm{m}^{2}\right)$ & 2283223 & 2734480 & 2882654 \\
CV $(\%)$ & 24 & 20 & 18 \\
$\operatorname{Min}\left(\mathrm{N} \cdot \mathrm{m}^{2}\right)$ & 1751145 & 2128314 & 2263018 \\
Max $\left(\mathrm{N} \cdot \mathrm{m}^{2}\right)$ & 3017357 & 3421467 & 3502289 \\
\hline Statistics & $\mathbf{9}$ par. & $\mathbf{1 7}$ par. & $\mathbf{3 3}$ par. \\
\hline $\bar{X}\left(\mathrm{~N} \cdot \mathrm{m}^{2}\right)$ & 3051033 & 3205942 & 4155601 \\
$\mathrm{Cv}(\%)$ & 16 & 16 & 15 \\
$\operatorname{Min}\left(\mathrm{N} \cdot \mathrm{m}^{2}\right)$ & 2343840 & 2478543 & 3205942 \\
$\operatorname{Max}\left(\mathrm{N} \cdot \mathrm{m}^{2}\right)$ & 3421467 & 3610052 & 4579917 \\
\hline
\end{tabular}

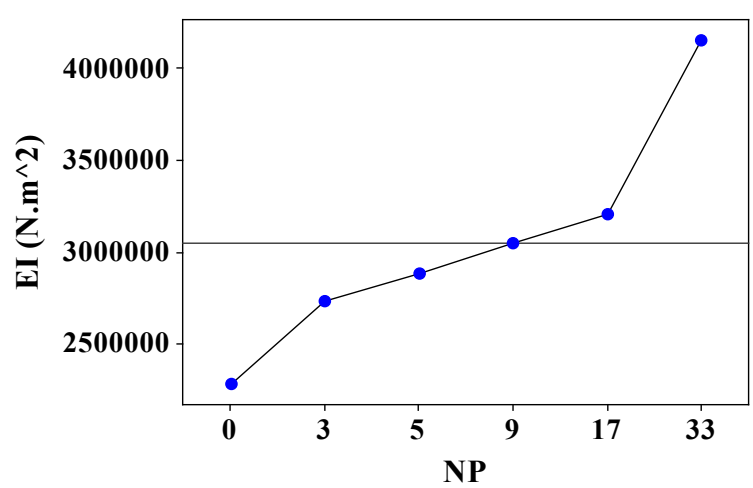

Figure 7. Mean values graphs of flexural stiffness as a function of screws number

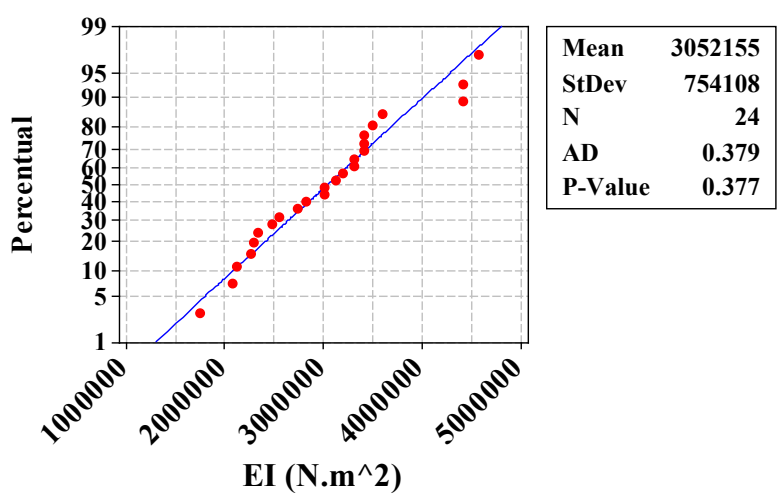

(a)

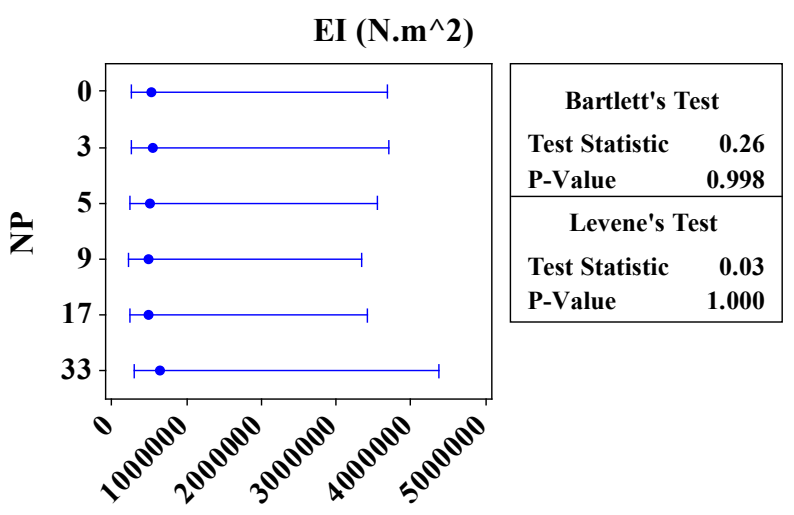

(b)

Figure 8. Normality tests (a) and variances homogeneity (b)

The characteristic value of parallel compression resistance of Eucalyptus sp. wood was equal to 32,4 MPA, which categorizes this variety in resistance class $\mathrm{C} 25$ of the hardwood group.

The P-values obtained from normality tests of Anderson-Darling $(0,998)$ and Bartlett $(0,377)$ were higher than the significance level (Figure 8), thus validating the ANOVA model. The P-value obtained from ANOVA for screws number in flexural stiffness values of the beams was equal to 0,003 , and because it is smaller than the significance 
level, it is verified that the screws number affected significantly in EI values of the beams (different means). Table 2 presents the Tukey test results.

Table 2. ANOVA and Tukey test results

\begin{tabular}{cc}
\hline EI & Tukey (Groupings) \\
\hline $0(100 \%$ Eucalipto $s p)$. & $\mathrm{C}$ \\
3 screws & $\mathrm{B}$ \\
5 screws & $\mathrm{B}$ \\
9 screws & $\mathrm{B}$ \\
17 screws & $\mathrm{B}$ \\
33 screws & $\mathrm{A}$ \\
\hline
\end{tabular}

From Table 2, it can be seen that flexural stiffness presented the lowest average value for 0 screws $(100 \%$ Eucalyptus), for 3, 5, 9 and 17 screws, the flexural stiffness values of tested beams presented intermediate EI values but statistically equivalent to each other, and that of 33 screws gave the highest flexural stiffness values. Thus, it is noted that 33 screws were presented as the configuration responsible for providing the highest stiffness value for the beams tested.

Table 3 presents the regression models tested results.

Table 3. Regression models tested results

\begin{tabular}{ccccc}
\hline \multirow{2}{*}{ Models } & \multirow{2}{*}{ P-value } & a & Coefficients & $\mathbf{R}^{2}$ \\
\hline Lin & 0.002 & 2600021.11 & 45217.98 & $97.15 \%$ \\
Exp & 0.001 & 2656958.06 & 0.0132 & $97.91 \%$ \\
Log & 0.032 & 2004803.06 & 534552.47 & $82.87 \%$ \\
Geo & 0.021 & 2218784.59 & 0.1589 & $86.69 \%$ \\
\hline
\end{tabular}

From Table 3 it can be seen that all regression models tested were significant in the stiffness estimation as a function of screws number (P-value $<0,05)$, and that both showed good fit quality $\left(\mathrm{R}^{2}>80 \%\right)$. Among the models, the best fit was obtained using the exponential model $\left(\mathrm{R}^{2}=\right.$ $97,91 \%)$, followed by linear $\left(R^{2}=97,15 \%\right)$, geometric $\left(R^{2}=\right.$ $86,69 \%$ ) and logarithmic $R^{2}=82,87 \%$ ). Figure 9 illustrates the exponential function adjustment to the set of mean stiffness values as a function of screws number used.

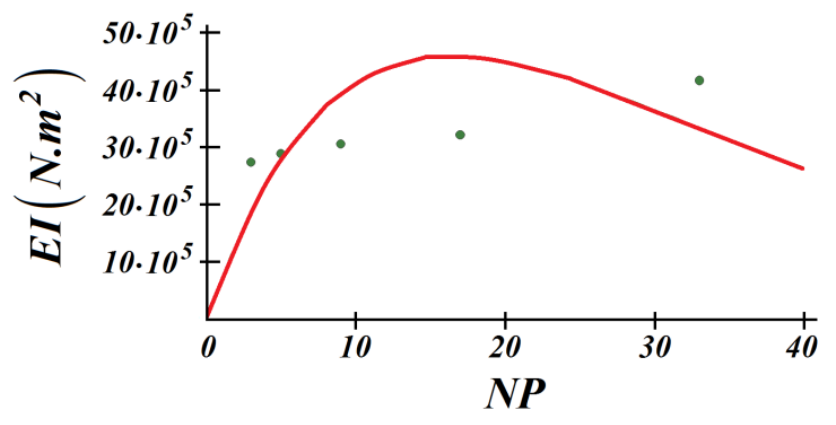

Figure 9. Fit graph by the exponential function (best model)

Due to the excellent exponential model precision and the adjusted function behavior, a possible increase in screws number exceeding 33 (higher value investigated) would not be able to increase the flexural stiffness values, of screws to be used in fixation of wooden beams tested here.

\section{Conclusions}

Based on what has been presented it is possible to conclude:

- The use of Pinus $s p$ wood treated in substitution of $66,6 \%$ of Eucalyptus $s p$ wood, and using the smaller amount of screws investigated (3), provided a significant increase in flexural stiffness values;

- Treatments 1, 2, 3 and 4 presented the same stiffness product;

- Treatment 5 presented a better stiffness product in relation to the other treatments, and the increase in screws number beyond this would cause a decrease in stiffness product, due to the cracking of the wood provided in standard with respect to minimum spacing. So this is the best possible treatment.

It is concluded that in cases of resources availability, and/or, necessity of best stiffness product, treatment 5 has proven to be the best option. Otherwise, treatment 1 proves to be the most viable, since treatments 2,3 and 4 do not present statistical improvement in stiffness product, thus avoiding waste of self-tapping screws.

\section{REFERENCES}

[1] Christoforo, A. L.; Arroyo, F. N.; Lopes, D. A.; Panzera, T. H.; Lahr, F. A. R. Full Characterization of Calycophyllum multiflorum Wood Specie. Eng. Agr-Jaboticabal, v. 37, p. 637-643, 2017.

[2] Cruz, H.; Nunes, L. A madeira como material de construção. Disponível em: <http://mestrado-reabilitacao.fa.utl.pt/discipl inas/jbastos/HCruzMadeiramateriall.pdf $>$. Acesso em: 03 out. 2015.

[3] Bertolini, M. S. ; Macedo, L. B. ; Almeida, D. H.; Icimoto, F. H.; Rocco Lahr, F. A. R. Restoration of Structural Timber Elements Using Epoxy Resin: Analysis of Mechanical Properties. Advanced Materials Research, v. 778, p. 582-587, 2013.

[4] Almeida, P. A. O. Madeira como material estrutural. Disponível em: $<$ http://www.lem.ep.usp.br/pef2402/METALICASEMADEI RAS-PEF 2402-APOSTILA.pdf>. Acesso em: 04 out. 2015.

[5] Cruz I. P.; Mendonça M. Comportamiento de las ligações madeira- resinas sintéticas e fibra de vidrio na restauração de peças estruturais. Tecnologia y Construccions, v. 18-1, p. 37-43, 2002.

[6] Custódio J.; Cabral-Fonseca S. Advanced fibrereinforced polymer (FRP) composites for the rehabilitation of timber and concrete structures: assessing strength and durability. Woodhead Publishing Series in Civil and Structural 
Engineering, p. 814-882, 2013.

[7] Nowak T. P.; Jasieńko J.; Czepiżak D. Experimental tests and numerical analysis of historic bent timber elements reinforced with CFRP strips. Construction and Building Materials, v. 40, p. 197-206, 2013.

[8] Pizzo B.; Gavioli M.; Lauriola M.P. Evaluation of a design approach to the on-site structural repair of decayed old timber end beams. Engineering Structures, v. 48, p. 611-622, 2013.
[9] Associação Brasileira de Normas Técnicas. NBR 7190: Projeto em estruturas de madeira: amostra. Rio de Janeiro, 107 p., 1997.

[10] Lahr, F. A. R.; Arroyo, F. N.; Almeida, T. H.; Almeida Filho, F. M.; Mendes, I. S.; Christoforo, A. L. Full Characterization of Erisma uncinatum Warm Wood Specie. International Journal of Materials Engineering, v. 6, p. 147-150, 2016. 